\title{
Educational prospects of Techno-CLIL strategies and implementation in the subject of History for the last triennium of Secondary schools
}

\author{
Maria Elisabetta Porcedda
}

Rebut: 29/01/2021 Acceptat: 31/01/2021

Key words: CLIL, teacher training, educational environment, ICTs, CLIL tools and models.

\begin{abstract}
Content and Language Integrated Learning (CLIL) was born in the '90s, explicitly aimed at fostering the European multilingualism at school, by means of the embedding content and foreign/minority languages, whose implementation non-linguistic subject teachers have been the only main characters for a long time. As a matter of fact, by now CLIL does not seem to be as widespread as wished in the European schools, often because it is not seen as an opportunity for teachers, but as a demanding topdown policy, both in training them and in workload for them. So, it is not perceived primarily in its global importance for a new kind of schooling, in which multilingualism is part of the holistic knowledge required to students of the XXI century, not the only real aim of CLIL, as the almost exclusively interest in it of the Foreign Languages (FLs) and Applied Linguistics Departments could demonstrate.

The research took into consideration especially the subject of History, at the basis of the European Union and its citizenship, because, thanks to its cross-curricula topics, and to its techniques and activities, which foster High Order Thinking Skills' (HOTS) development for students (Coyle, 2015), and language learning as well (Marsh, 2012), in Europe it is the first subject implemented through CLIL. Techno-CLILa, namely CLIL through the adoption of ICTs, is also suggested as answer to the common students' need of new approaches and new modern tools to study this subject (Krutka \& Carpenter, 2016).

In order to involve further teachers in the implementation of the Technological CLIL, as key to change common schooling (by now teacher-centered, not aimed at the transversal, holistic and competencebased knowledge of students, as well as too often not taking advantage of ICTs), this thesis had got four general objectives to reach, sequential but all also independently contributing to the European research on CLIL:
\end{abstract}

\footnotetext{
a The term Techno-CLIL was created by Cuccurullo and Cinganotto for an International MOOC (Massive Open Online Course) of TESOL (Teaching English to Speakers of Other Languages) International. See: https://www.agendadigitale.eu/scuoladigitale/strumenti-digitali-per-insegnare-le-lingue-straniere-il-metodo-clil/\#post-56127-footnote-3.
} 
- Find out the affordances of the CLIL implementation for non-linguistic subject teachers, so as to define CLIL in an engaging way for them.

- Consider previous positives, negatives and/or lacks emerged in the CLIL training for teachers, in order to suggest a proper path for Technological CLIL training.

- Look for the best strategies and tools within the implementation of Techno-CLIL into History in the last triennium of Secondary schools (namely for 16-18 years old students).

- Build some models of Techno-CLIL to suggest in History context, emerged by the previous points.

The complexity of CLIL, especially by means of ICTs, together with these demanding objectives, led to different kinds of methodologies, such as systematic and narrative reviews, to achieve theoretical answers, and a phenomenological approach with a manually a posteriori codification of the texts, obtained by the qualitative data of a critical participatory action research in three Licei Linguistici in Italy, in order to design concrete tools for CLIL teacher training and implementations.

In particular, the thesis is divided into three Theoretical Frameworks and an Empirical part.

The first theoretical framework focused on both CLIL literature, in particular those coming from authors considered such as historical building blocks (Marsh, Coyle, Ball, etc.), and from European Directives about Education, concerning goals to achieve in studies and the ongoing process of CLIL practice in all States. Indeed, the "only" aim of plurilingualism, rooted in the CLIL since its inception, is not sufficient to involve non-linguistic subject teachers with its workload. They need to see affordances of CLIL from the literature from their point of view, especially concerning its definition. Thus, understanding what CLIL is, the meaning of Content and Language, strictly related as explicit aims of the dual-focused CLIL, but also tools for one another in the meaning-making of students, rooted in the social-constructivism, taskbased, is not easy, because of its complexity (Is it an approach? A method? And so on). It emerges clearly from the various CLIL models, and then from the identification of the required competencies of the main stakeholders, namely teachers and students, involved in the subject of History. In order to plan and implement CLIL, whose main results are recognised in motivation and engagement, there are for teachers many theoretical and strategical choices, which affect in practice the outcomes to achieve for the students, the role of the teacher within the class, the tools to use for the activities and also the disposition of students and workstations in the class. This is why the 4 Cs model, by Do Coyle, guides all the others, although all useful contributions for planning in particular, so as to reach cognitive and communicative goals of students, other than cultural and of knowledge, in different ways and through different strategies, with no precise rules to see as an advantage, not a limit. So, according to the European Directives, answering to the first objective, we define CLIL as an educational environment, demanding but significant for both teachers and students, highly inclusive, because absolutely studentcentred and open to different attitudes, in teaching and learning, to pre-requisites of students, and teachers' pre-training (in Content or FLs) and objectives, so participative. In this environment, based on cooperative tasks, as much as possible transmedia, highly communicative and inclusive, and on scaffolding, of teachers and peers, evaluation should be formative, fostering pluriliteracies. This evaluation is seen as a pillar of a new kind of schooling, on the way to the XXI century skills, above all the Learning to Learn for the community of teaching and learning (Porcedda \& González, 2020a).

This change of schooling by means of Techno-CLIL needs to rethink the teacher training. So, the second Theoretical Framework focused on the CLIL training in the literature, in order to identify its weaknesses, and, on the other side, the suggestions, from the stakeholders in particular, so as to fill these gaps and obtain a path for CLIL training. As a matter of fact, teaching through CLIL, according to our definition, is aimed at participatory schooling and holistic learning, for which teachers should be adequately prepared. 
This is what another systematic literature review made emerge, through a systematic procedure including a planned categorial analysis of European CLIL qualitative and mixed data (Porcedda \& González, 2020b): it is to consider as whenever and wherever valid learning by doing in collaboration, better if in cooperative teaching teams, with sharing of knowledge and competences (particularly important between content and FL teachers), as a crucial point of the needed lifelong learning. Especially cross-cutting multidisciplinary blended courses at University, which normally certifies the teachers' training, are highly suggested, in order to learn in the same way of students. But to change effectively our schooling, it results to be opportune starting from pre-service, for which Departments of Education, with others as Linguistics and History ones, should guide CLIL training, because Pedagogical and Instructional gaps are felt as the main relevant, conversely to the FL training put as first by FL Departments, which now guide this training in almost all Europe.

The third Theoretical Framework answers to some relevant questions, emerged from the previous Frameworks:

- Is there a "CLIL pedagogy"? Whilst many researchers are divided in considering CLIL a specific pedagogy, because of the features of its dual aims, or of specific bilingual pedagogies, like codeswitching and translanguaging, the literature (although not wide for this field), highlights within CLIL the adoption of these pedagogies, which have got common points among them, but which are perceived by teachers as engaging and motivating choices to vary just why different. So CLIL confirms to be an open environment for pedagogies too, far from a "pedagogical vagueness". But it is a richness in which teachers should be absolutely trained.

- Which linguistic approaches are linked to and suggested for CLIL? As seen before, multilingualism was often the first aim of CLIL, and its training is guided by Linguistics Departments so far. Despite this, we have underlined, according to the literature, as the variety of Linguistic Approaches (LA), though with a clear prevalence of the adoption of the Communicative one, linked to different pedagogies, offers teachers appropriate CLIL strategies in different contexts, and should be their essential background, so should take part to their training, for an aware use of them in their classrooms.

- Concerning ICTs: How are they relevant within Communication and Cognition? Are there models for their integration at school in the literature, useful for CLIL teachers? Are in the CLIL literature suggestions for educational integrated methodological approaches? The role and importance of ICTs could not be subtended, given that they are crucial for a new kind of schooling through CLIL, and the literature shows that their adoption offers wider authentic learning scenarios, inclusive and various, so for all and each student, which foster their acquirement of XXI century skills. But, to arrive to it, teachers' digital competence should be paid attention, and the European tool of DigComEdu can measure it and steer their ICTs' use, so as to give students multimedia inputs, taking advantage of the instructional opportunities of the participatory and convergence culture by means of their networked transmedia storytellings, as parts of the creative community of the Web. As useful tools for teachers and their trainers, the literature suggests: the SAMR Model (Puentedura, 2006 ${ }^{\mathrm{b}}$ ), so as to guide the aware use of ICTs within teaching and learning, in order to deeply change Education, and the related Padagogy Wheel of Carrington', which supports SAMR, adding suggestions for a pedagogical use of apps, related to the four levels of its technological integration; the TPACK (Technology Pedagogy and Content Knowledge) (Koehler \& Mishra, 2009), which fosters the creativity and design of technologyintegrated lessons, and the curricula for specific and concrete contexts and subjects through the interactions among content, pedagogy, and technology, yet tried within CLIL; and finally the

\footnotetext{
${ }^{\mathrm{b}}$ In www.hippasus.com

${ }^{c}$ https://designingoutcomes.com/the-padagogy-wheel-v4-0-the-next-generation/
} 
EdTech Quintet, which considers together the two previous frameworks, giving good results in teacher training and fostering the accurately planning for a pedagogical ICTs' use in classroom (so it has been taken into consideration in the empirical part of this research). Finally, the literature shows these, and only these, educational integrated methodologies for Technological CLIL: Digital Storytelling, Flipped Classroom, Cooperative Learning, WebQuests, Project-based Learning, Gamification, Digital Game-based Learning (DGBL).

All the above theoretical results have been at the basis of the Empirical Part of the thesis, in order to answer to the last two objectives of the thesis, and to other two questions arose from the second Theoretical Framework:

- Can ICTs be important also in FL competence and pedagogical preparation?

- Is team teaching an answer to the lack of knowledge in language acquisition?

The chosen paradigm was the critical participatory action research, because of my role of applied researcher, as well as in the belief that the stakeholders at school are profoundly interested to change schooling, in their concrete practices, reflecting on their consequence and appropriateness, as researchers (Kemmis et al., 2014). Mainly narrative data from them have been so assumed through different instruments (initial and final questionnaires; recordings, video, pictures; fieldnotes and comments; Padlet with lesson plans, students' works and teachers' comments; a monitoring grid, built by us, according to the results of the Theoretical Frameworks, in Porcedda \& González, 2019) to understand in-depth the complexity of social relationships and the contemporary adoption of various pedagogies, LA and integrated methodologies, other than tools.

15 teachers (but 89 answered to the initial questionnaires) and 166 students were fully involved. All the theoretical frameworks led to the adoption of blended courses, so planned by us, in order to give teachers firstly knowledge about CLIL and its tenets, because almost all inexperienced, although CLIL is compulsory in Secondary schools; then to form teams, at least for planning through a given lesson plan and rubrics of evaluation and students' self-assessment, but above all to acquire their democratic contribution to the reflexion on Techno-CLIL practice, in its complexity. So, sayings, doings and relatings of the three involved subjectivities (teachers, students, and the researcher) have been assumed as the most powerful force for changing educational practice, then related to the founded a-posteriori categories of: Knowledge, Implementation, Communication, Collaboration, Engagement, Evaluation, with their indicators. The chosen model of analysis of these categories was based on SWOT, (Strengths, Weaknesses, Opportunities, Threads), but substituting Threads with Difficulties and Suggestions (SWODS).

The results of the analysis from the empirical data concern firstly teachers. Indeed, there were involved content teachers of both biennium and triennium, with peculiar but positive goals for both of them, according to their judgement: the former particularly in academic vocabulary in all the involved languages, ancient (Greek) and modern (English, Spanish, German), MT as FLs, other than in engagement and motivation, whilst the latter underlined through the students' tasks more cultural elements of transcurricular topics, especially for teachers' teams. This result is valid also regarding involved content and/or FL teachers. For all, MT should be deepened together with FL, and ICTs offer teachers with low levels of FL the opportunity to implement CLIL in a participatory environment with students. They stress as crucial point the importance of: 1) teams, in teaching as in groupworks, and particularly in planning and evaluating, highly motivating for both teachers and students, which highlight the pluri-dimension of History (linguistic as well); 2 ) the adoption of transversal plurilingual multi-faceted topics, through which cooperatively building their products and obtaining their holistic vision of them. But it is not to underestimate the role of hybrid content or FL teachers (Ball et al., 2015), so implementing alone, as an initial training preparatory to teams, also because these are not easily agreed. 
If implementation is concerned, the results provided some suggestions on how teachers should plan an intervention for CLIL: 1) There are the need of a guide through tools as lesson plans and grids, also in MT in an initial phase (which result to foster translanguaging and codeswitching); 2) SAMR and EdTech Quintet are welcomed by teachers as a ladder for planning engaging tasks, in the respect of students' diversities in learning; 3) Planning should start from the interdisciplinary competence-based $4 \mathrm{Cs}$, in participatory and technological environment (as social media); 4) Tasks are aimed at participative transmedia products of Digital Storytelling of students; 5) Rubrics of evaluation should guide both teachers' intervention and students' paths (formative assessment), and are to build and agreed together; a reflexion post-implementation fosters the learning-to-learn of students and the life-long-learning of teachers, other than the CLIL participative environment.

Finally, the results about the instructional choices evidenced that: 1) Genre and Social-constructivism were the most adopted pedagogies, together with the Communicative Linguistic Approach; 2) Digital Storytelling has been welcomed by almost all teachers and students (but the latter asked for further involvement in the choice of topics and online tools), partially Gamification (mostly adopted by FL teachers), whilst teacher-centered approaches affected the choice of the other methodologies in the CLIL literature.

These results meant that two different models were needed to guide the Techno-CLIL teachers' implementation: one for teams and one for hybrid teachers. They both include the educational and instructional findings of this research, but under different dimensions, arising from Coyle's models (Coyle et al., 2010):

- The Genre CLIL Model, whose specific Design of Implementation we suggest follows the Conceptual, Procedural, Linguistic dimensions, according to the Three Dimensional Model (Ball et al., 2015);

- The Teaching Team Model, whose specific Design of Implementation we suggest follows the dimensions of Knowledge, Action, Evaluation, according to the Pluriliteracies Model of the European Center of Modern Languages (Meyer et al., 2015).

Both these models include a Lesson Plan, reviewed by us, with concrete suggestions of instructional choices and tools by phases.

Concluding, it can be said that the complexity of the Techno-CLIL could be expressed by the keywords of demanding and progression, which are at the basis of the same putting it into practice in teaching and learning. This is why, as well as in training, as seen, Techno-CLIL implementation needs to be concretely guided, and the research in this field can be considered always in fieri.

\section{References}

Ball, P., Kelly, K., and Clegg, J. (2015). Putting CLIL into Practice. University Press

Coyle, D., Hood, P., and Marsh, D. (2010). CLIL: Content and language integrated learning. Cambridge University Press 
Kemmis, S., McTaggart, R., \& Nixon, R. (2014). The action research planner: Doing critical participatory action research. Springer

Koehler, M. J., \& Mishra, P. (2009). What is Technological Pedagogical Content Knowledge (TPACK)? Contemporary Issues in Technology and Teacher Education, 9(1), 60-70.

Meyer, O., Coyle, D., Halbach, A., Schuck, K., \& Ting, T. (2015). A pluriliteracies approach to content and language integrated learning - mapping learner progressions in knowledge construction and meaning-making. Language, Culture and Curriculum, 28(1), 41-57.

Porcedda, M. E., \& González-Martínez, J. (2019). Learning from Mistakes and Detecting Specific Training Needs: A CLIL Grid. In Pixel (Ed.), Innovation in Language Learning - 12th International Conference (pp. 41-45). Filodiritto

Porcedda, M. E., \& González-Martínez, J. (2020a). ¿Por qué AICLE? Un análisis de la literatura desde la perspectiva de los docentes de materias no lingüísticas. Universitas Tarraconensis. Revista de Ciències de l'Educació, 1(1), 37-51.

Porcedda, M. E., \& González-Martínez, J. (2020b). Teacher Training in Content and Language Integrated Learning: lacks and suggestions from a systematic literature review. Enseñanza \& Teaching, 38, 1-2020, 49-68. 